\title{
Nucleotides and AHCC Enhance Th1 Responses In Vitro in Leishmania-Stimulated/Infected Murine Cells
}

\author{
María Auxiliadora Dea-Ayuela ${ }^{1}\left(\mathbb{D}\right.$, Sergi Segarra ${ }^{2, *}$, Dolores R. Serrano ${ }^{3,4}(\mathbb{D}$ and \\ Francisco Bolás-Fernández ${ }^{5}$ \\ 1 Departamento de Farmacia, Facultad de Ciencias de la Salud, Universidad CEU-Cardenal Herrera, \\ 46113 Moncada, Spain; mda_3000@yahoo.es \\ 2 R \& D Bioiberica S.A.U., Av. dels Països Catalans 34, 08950 Esplugues de Llobregat, Spain \\ 3 Department of Pharmaceutics and Food Technology, School of Pharmacy, \\ Universidad Complutense de Madrid, Plaza Ramon y Cajal s/n, 28040 Madrid, Spain; \\ dr.serrano@farm.ucm.es \\ 4 Instituto Universitario de Farmacia Industrial (IUFI), School of Pharmacy, \\ Universidad Complutense de Madrid, Avenida Complutense, 28040 Madrid, Spain \\ 5 Departament of Microbiology and Parasitology, School of Pharmacy, Universidad Complutense de Madrid, \\ Plaza Ramon y Cajal s/n, 28040 Madrid, Spain; francisb@farm.ucm.es \\ * Correspondence: ssegarra@bioiberica.com; Tel.: +34-9349-04908
}

Received: 29 July 2020; Accepted: 25 August 2020; Published: 27 August 2020

\begin{abstract}
A stronger Th1 (cellular) immune response in canine leishmaniosis (CanL) leads to a better prognosis. Dietary nucleotides plus AHCC ${ }^{\circledR}$ have shown beneficial effects in dogs with clinical leishmaniosis and in clinically healthy Leishmania-infected dogs. The potential leishmanicidal activity of nucleotides and AHCC was assessed by quantifying nitric oxide (NO) production and replication of parasites. Their effects on lymphocyte proliferation were studied with and without soluble Leishmania infantum antigen (SLA) stimulation. Cytokine level variations were assessed using naïve and $L$. infantum-infected macrophages/lymphocytes cocultures. Promastigotes and amastigotes proliferation and NO macrophage production were not directly affected. Lymphocyte proliferation was significantly enhanced by nucleotides, AHCC, and their combinations only after SLA stimulation. Nucleotides and AHCC significantly increased the production of IL-1 $\beta$, IL-2, IL-5, IL-9, IL-10, and IL-12 by naïve immune cells. In naïve and L. infantum-infected macrophage/lymphocyte cocultures, nucleotides with or without AHCC led to significant increases in IFN- $\gamma$ and TNF- $\alpha$. Given that these cytokines are involved in the effective Th1 immune response against Leishmania parasites, these mechanisms of action could explain the previously reported in vivo clinical efficacy of such combination and further support the use of nucleotides with or without AHCC in the management of CanL patients.
\end{abstract}

Keywords: nucleotides; AHCC; Leishmania spp; Th1 response; cytokines; promastigotes; amastigotes; mechanism of action

\section{Introduction}

Unicellular flagellates of the family Trypanosomatidae are obligatory parasites of invertebrates, vertebrates, and plants. This family includes pathogens responsible for African sleeping sickness, Chagas' disease, and leishmaniases, among others. The subfamily Leishmaniinae includes monoxenous parasites of insects and dixenous parasites of insects and vertebrates (genera Leishmania, Paraleishmania and 'Endotrypanum') [1,2]. Leishmaniasis is a complex of infectious diseases caused by protozoan parasites belonging to species of the genus Leishmania. These diseases affecting humans and several wild and domestic mammals are transmitted by Diptera arthropods belonging to genus Lutzomyia in 
the New World or Phlebotomus in the Old World [3]. The clinical spectrum of the disease is largely dependent on the infecting species and the intrinsic characteristics of the host, varying from the benign cutaneous forms to the most severe form, visceral leishmaniasis, which is fatal if left untreated [4].

In urban areas, domestic dogs are the main parasite reservoir which effectively takes part in its transmission. The decision on whether or not to treat seropositive dogs is still under debate given that treatment can be toxic to animals and generate drug resistances, which may be extended to humans. Very few drugs are available at the clinical level; therefore, the search for new therapies for both humans and animals is an urgent task [5]. Pentavalent antimonials (SbV) are the current first-choice drugs prescribed by veterinary practitioners against canine leishmaniosis (CanL) in Mediterranean countries (either alone or in combination with allopurinol) [6]. However, despite their proven leishmanicidal activity, SbV-based drugs have some drawbacks, including high price, undesired side effects following parenteral administration and development of resistances, which encourage their replacement by safer treatments $[7,8]$. Likewise, allopurinol resistance has also recently been reported in L. infantum parasites isolated from dogs undergoing allopurinol treatment, and associated with clinical relapse [9]. Other oral therapies, such as miltefosine, have shown a high incidence of resistance as well as many adverse effects including teratogenicity and gastrointestinal disorders [10].

The natural susceptibility and clinical evolution of CanL patients strongly depends on the type of immune response elicited in the dog after infection. According to Reis et al. [11], the evaluation of different factors such as parasite burden, humoral response, cell-mediated immunity, or cytokine expression, have a predictive value on the progression of infection and should, therefore, be considered as key markers of resistance and susceptibility to CanL. Increased levels of certain parameters such as parasite load, IL-10, TGF- $\beta$, or Leishmania-specific IgG, IgM, IgA, and IgE serum antibodies are indicators of disease progression. By contrast, increased levels of peripheral blood mononuclear cells (PBMC) proliferation after leishmanial antigen stimulation, interferon gamma (IFN- $\gamma$ ) and tumor necrosis factor alpha (TNF- $\alpha$ ) expression, proliferation of $\mathrm{CD} 4+, \mathrm{CD} 8+$, and B-cell subsets, or a positive Leishmania skin test (LST) are associated with resistance [12]. Accordingly, increased levels of IFN- $\gamma$ in cured cases have been reported [13]. Previously, it has also been described that an elevation in the production of IL-10 is associated with deficient CD4+ T cell effector responses during clinical visceral leishmaniasis. In dogs, CD4+ and CD8+ T cell exhaustion has been described as a significant stepwise loss of Ag-specific proliferation and IFN- $\gamma$ production, linked to clinical worsening [14].

Nucleotides are low molecular weight intracellular compounds that play key roles in biochemical processes. Sources include de novo synthesis, recovery via salvage mechanisms, and dietary intake. Although endogenous production serves as the main nucleotide source, evidence suggests that exogenous supply is essential to immune competence, intestinal development, and recovery. Thus, nucleotides become essential in certain situations where there is physiological stress and an increased demand for nucleic acid synthesis, including immunosuppression, infection, and some disease states [15]. Orally administered nucleotides modulate the immune response, having a positive impact on lipid metabolism and immunity, tissue growth, development, and repair. They can also be particularly beneficial in situations when rapidly proliferating tissues, such as the intestine and the immune system, fail to fulfil their nucleotides needs by de novo synthesis. Therefore, dietary nucleotides are considered as potential immuno-modulatory compounds [16,17].

On the other hand, AHCC ${ }^{\circledR}$, a standardized extract of cultured Lentinula edodes mycelia (ECLM), stimulates the immune system in humans [18]. Among other actions, AHCC has been reported to increase Th1 cell responses [18-21] and to exert immunomodulatory effects on intestinal epithelial cells and macrophages [22], probably throughout the regulation of TLR2 and TLR4 signaling [23], which could potentially benefit Leishmania-infected dogs.

In a recent multicenter open-label positively-controlled clinical trial, sixty-nine dogs with naturallyoccurring clinical leishmaniosis were randomized to receive allopurinol or nucleotides plus AHCC orally once daily for 180 days in addition to an initial 28-day course of methylglucamine antimoniate (MGA). The combined use of MGA and nucleotides plus AHCC resulted in improved clinical scores 
and an overall amelioration in the biomarkers used to monitor response to treatment, showing similar efficacy to MGA plus allopurinol, and without producing xanthinuria [24]. Furthermore, in another recent multicenter, randomized, double-blind, placebo-controlled trial, 1-year administration of dietary nucleotides plus AHCC in clinically healthy dogs naturally infected with L. infantum led to a significantly reduced disease progression rate compared to placebo, and a decrease in the levels of anti-Leishmania antibodies indicating that dietary nucleotides plus AHCC could potentially be used as a preventive approach [25].

The present work was aimed at assessing the in vitro effects of nucleotides and AHCC on murine lymphocyte proliferation and cytokine production upon stimulation with leishmanial antigens as well as on Leishmania infectivity to macrophages cocultured with lymphocytes to better characterize the cellular and molecular bases of the potential immunomodulatory effects of these compounds.

\section{Results}

\subsection{Cytotoxicity Studies on Murine Macrophages}

The toxicity of the nucleotides and AHCC alone was tested by preparing serial dilutions of both compounds starting at concentrations of $400 \mu \mathrm{g} / \mathrm{mL}$. No cell toxicity was observed for any of the compounds at any of the tested dilutions, suggesting that the $\mathrm{CC}_{50}$ (cytotoxic concentration 50) was well above $400 \mu \mathrm{g} / \mathrm{mL}$ (see Supplementary Material 1).

\subsection{Production of Nitric Oxide (NO) by Macrophages}

The production of NO by macrophages was not altered following the application of compounds alone or with any of the combinations (see Supplementary Material 2) suggesting that the in vivo efficacy of nucleotides plus AHCC in CanL patients previously reported $[24,25]$ probably occurs through a different mechanism of action.

\subsection{In Vitro Promastigote and Amastigote Susceptibility Assays}

No in vitro changes were observed with the compounds alone or with any of the combinations on parasites growth, thus indicating that nucleotides and AHCC do not elicit a direct activity against the parasites (see Supplementary Material 3).

\subsection{In Vitro Lymphoproliferation Assay}

Nucleotides and AHCC, tested alone or at a 1:1 ratio at final concentrations of 200, 50, and $12.5 \mu \mathrm{g} / \mathrm{mL}$, did not show any significant $(p<0.05)$ proliferation enhancement effects on murine lymphocytes compared to the control (Figure 1a). In contrast, after soluble Leishmania infantum antigen (SLA) stimulation, nucleotides and the 1:1 combination of nucleotides with AHCC were able to significantly increase lymphocyte proliferation compared to the control (Figure 1b), hence counteracting the antiproliferative effect exerted by the parasite antigen. 




(a)

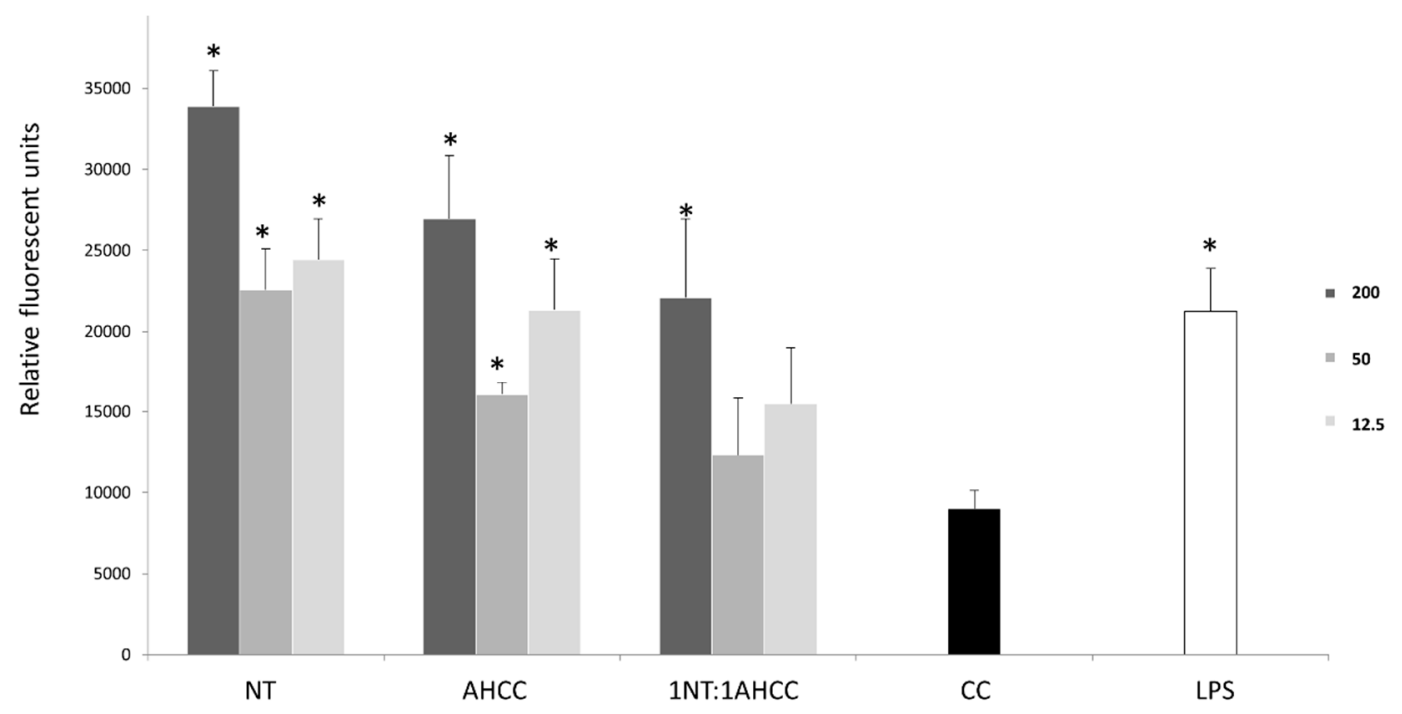

(b)

Figure 1. Effect of nucleotides (NTs), AHCC, and their 1:1 combination at concentrations of 200, 50, and $12.5 \mu \mathrm{g} / \mathrm{mL}$ on lymphocyte proliferation before (a) and after (b) soluble Leishmania infantum antigen (SLA) stimulation. * $p<0.05$ versus control cells (CC).

\subsection{Analysis of Cytokines}

A concentration of $200 \mu \mathrm{g} / \mathrm{mL}$ was used for the test compounds in the studies aimed at quantifying cytokine production because this was the one that provided the best results in the proliferation studies (Figure 1a,b). Moreover, given that the proliferation studies revealed that the addition of the compounds could counteracted the antiproliferative effect of SLA (Figure 1b), cytokine levels were quantified in naïve but also in L. infantum-infected macrophage/lymphocyte cocultures (Table 1 and Figure 2). 
Table 1. Cytokine quantification after exposure to nucleotides (NTs), AHCC, and their combinations in lymphocyte culture with or without SLA stimulation. Each value represents the mean $+/-$ standard deviation for three replicates. ${ }^{*} p<0.05$ versus the control.

\begin{tabular}{|c|c|c|c|c|c|c|c|c|}
\hline Concentration $(\mathrm{pg} / \mathrm{mL})$ & $\mathrm{CC}$ & NT & 1NT:1AHCC & 2NT:1AHCC & NT + SLA & 1NT:1AHCC + SLA & 2NT:1AHCC + SLA & LPS \\
\hline GM-CSF & $0+/-0$ & $0+/-0$ & $0+/-0$ & $1+/-0$ & $2+/-0$ & $1+/-0$ & $2+/-0$ & $0+/-0$ \\
\hline IFN- $\gamma$ & $3+/-0$ & $2+/-0$ & $4+/-0$ & $2+/-0$ & $9+/-0$ * & $5+/-0$ * & $9+1-0$ * & $4+/-0$ \\
\hline IL- $1 \alpha$ & $0+/-0$ & $0+/-0$ & $0+/-0$ & $0+/-0$ & $0+/-0$ & $0+/-0$ & $0+/-0$ & $2+/-1$ \\
\hline IL-1 $\beta$ & $1+/-0$ & $3+/-1$ & $1+/-0$ & $1+/-0$ & $3+/-0$ & $1+/-0$ & $3+/-0$ & $0+/-0$ \\
\hline IL-2 & $0+/-0$ & $2+/-0$ & $1+/-0$ & $7+/-1 *$ & $9+/-1$ * & $8+/-0 *$ & $11+/-1$ * & $0+/-0$ \\
\hline IL-3 & $0+/-0$ & $0+/-0$ & $0+/-0$ & $0+/-0$ & $0+/-0$ & $0+/-0$ & $0+/-0$ & $0+/-0$ \\
\hline IL-4 & $0+/-0$ & $0+/-0$ & $0+/-0$ & $0+/-0$ & $0+/-0$ & $0+/-0$ & $0+/-0$ & $0+/-0$ \\
\hline IL-5 & $0+/-0$ & $0+/-0$ & $0+/-0$ & $0+/-0$ & $0+/-0$ & $0+/-0$ & $0+/-0$ & $0+/-0$ \\
\hline IL-6 & $4+/-0$ & $5+/-0$ & $19+/-2$ * & $24+/-2$ * & $9+/-1 *$ & $25+/-3$ * & $26+/-2 *$ & $1229+/-7$ * \\
\hline IL-9 & $48+/-5$ & $62+/-10$ & $50+/-4$ & $79+/-3$ * & $103+/-10$ * & $33+/-3$ & $114+/-7^{*}$ & $138+/-12$ * \\
\hline IL-10 & $0+/-0$ & $0+/-0$ & $5+/-0$ & $19+/-1$ * & $5+/-0$ & $0+/-0$ & $0+/-0$ & $45+/-2 *$ \\
\hline IL-12 & $2+/-0$ & $2+/-0$ & $4+/-0$ & $5+/-0$ * & $5+/-0$ * & $1+/-0$ & $4+/-0$ & $4+/-0$ \\
\hline IL-13 & $0+/-0$ & $0+/-0$ & $0+/-0$ & $0+/-0$ & $0+/-0$ & $0+/-0$ & $0+/-0$ & $0+/-0$ \\
\hline IL-17 & $0+/-0$ & $0+/-0$ & $0+/-0$ & $0+/-0$ & $1+/-0$ & $0+/-0$ & $0+/-0$ & $1+/-0$ \\
\hline $\mathrm{KC}$ & $0+/-0$ & $0+/-0$ & $0+/-0$ & $0+/-0$ & $0+/-0$ & $0+/-0$ & $0+/-0$ & $38+/-1$ \\
\hline MCP-1 & $0+/-0$ & $12+/-1$ * & $4+/-0$ & $8+/-1$ * & $12+/-1$ * & $0+/-0$ & $9+/-0$ * & $0+/-0$ \\
\hline M-CSF & $0+/-0$ & $0+/-0$ & $0+/-0$ & $0+/-0$ & $0+/-0$ & $0+/-0$ & $1+/-0$ & $0+/-0$ \\
\hline RANTES & $1+/-0$ & $1+/-0$ & $0+/-0$ & $1+/-0$ & $0+/-0$ & $0+/-0$ & $0+/-0$ & $82+/-2$ * \\
\hline TNF- $\alpha$ & $0+/-0$ & $0+/-0$ & $0+/-0$ & $0+/-0$ & $12+/-1$ * & $0+/-0$ & $10+/-0$ * & $0+/-0$ \\
\hline VEGF & $0+/-0$ & $0+/-0$ & $0+/-0$ & $0+/-0$ & $0+/-0$ & $0+/-0$ & $0+/-0$ & $1+/-0$ \\
\hline
\end{tabular}




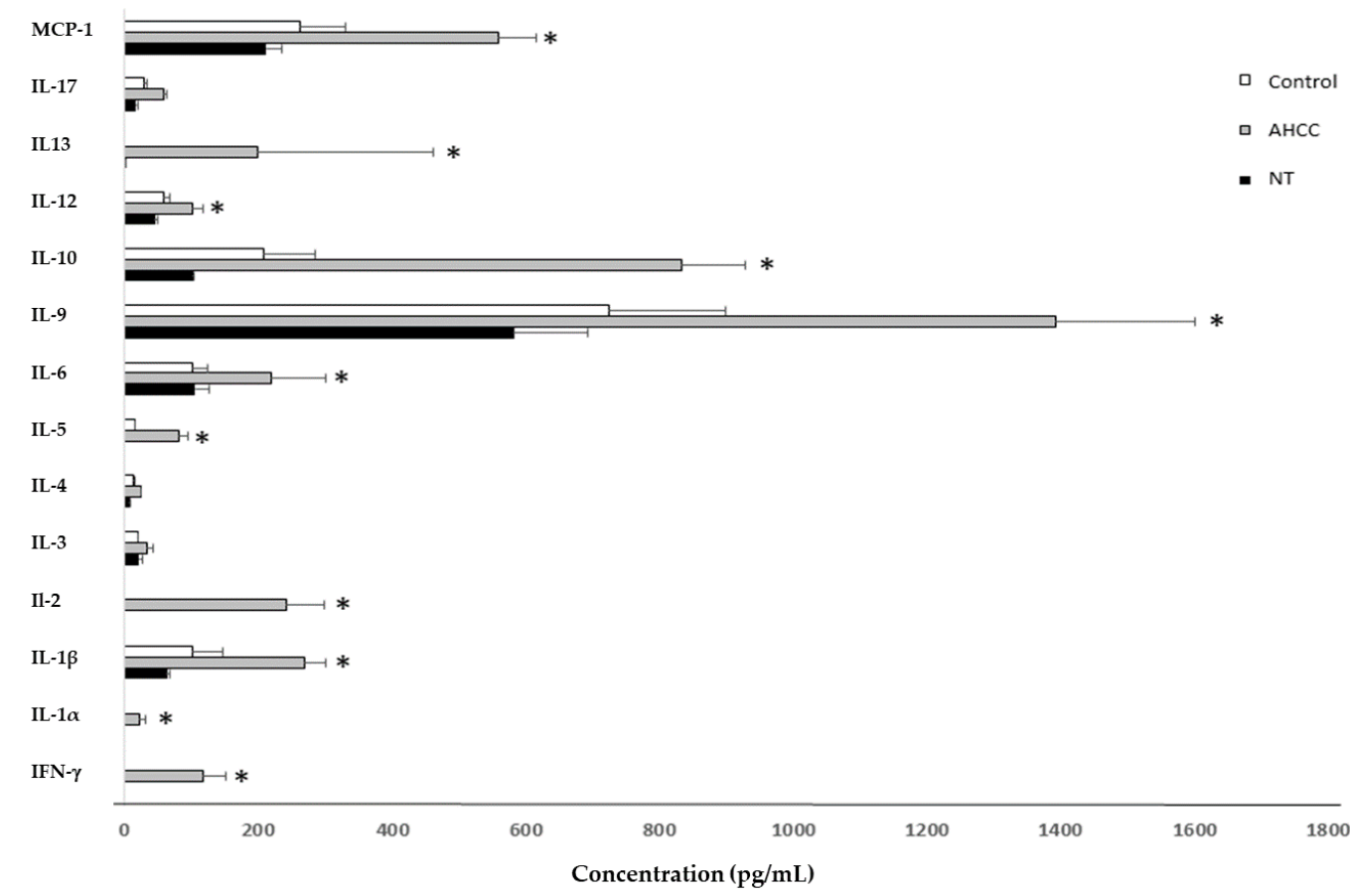

Figure 2. Comparison of cytokine production by lymphocytes isolated from BALB/c mouse spleen after $24 \mathrm{~h}$ exposure to nucleotides (NTs) and AHCC. ${ }^{*} p<0.05$ versus the control.

\subsubsection{Coculture of Lymphocytes and Naïve Macrophages}

The results are shown in Table 2. TNF- $\alpha$ levels were significantly increased with nucleotides either alone or in combination with AHCC, compared to the control (Figure 3a). Nucleotides, AHCC, and their 1:1 and 2:1 combinations led to significantly increased levels of IFN- $\gamma$, compared to the control (Figure 3b). Similar effects were found for IL-1 $\beta$, IL-6, IL-12, IL-17, and RANTES. The combination of both compounds led to a significant increase in IL-9. The levels of MCP-1 were significantly increased by AHCC and the 1:1 and 2:1 combinations with nucleotides, compared to the control.

Table 2. Cytokine quantification after exposure to nucleotides (NTs), AHCC, and their combinations in cocultures of lymphocytes and naïve macrophages. Each value represents the mean $+/-$ standard deviation for three replicates. ${ }^{*} p<0.05$ versus the control.

\begin{tabular}{cccccc}
\hline Concentration (pg/mL) & CC & AHCC & NT & 1NT:1AHCC & 2NT:1AHCC \\
\hline GM-CSF & $0+/-0$ & $0+/-0$ & $0+/-0$ & $0+/-0$ & $0+/-0$ \\
IFN- $\gamma$ & $0+/-0$ & $15+/-2 *$ & $54+/-13 *$ & $84+/-9 *$ & $121+/-12 *$ \\
IL-1 $\alpha$ & $0+/-0$ & $24+/-12 *$ & $103+/-19 *$ & $36+/-10 *$ & $26+/-11 *$ \\
IL-1 $\beta$ & $0+/-0$ & $0+/-0$ & $20+/-5 *$ & $84+/-3 *$ & $113+/-12 *$ \\
IL-2 & $0+/-0$ & $0+/-0$ & $1+/-0$ & - & $1+/-0$ \\
IL-3 & $0+/-0$ & $0+/-0$ & $0+/-0$ & $6+/-1 *$ & $6+/-1 *$ \\
IL-4 & $0+/-0$ & $0+/-0$ & $0+/-0$ & $0+/-0$ & $0+/-0$ \\
IL-5 & $0+/-0$ & $0+/-0$ & $2+/-1$ & $26+/-7 *$ & $32+/-10 *$ \\
IL-6 & $50+/-6$ & $86+/-9 *$ & $60+/-5$ & $168+/-18 *$ & $133+/-8 *$ \\
IL-9 & $188+/-29$ & $0+/-0$ & $134+/-21$ & $341+/-47 *$ & $382+/-64 *$ \\
IL-10 & $0+/-0$ & $0+/-0$ & $0+/-0$ & $0+/-0$ & $18+/-3 *$ \\
IL-12 & $4+/-1$ & $1+/-0$ & $14+/-1 *$ & $22+/-3 *$ & $28+/-2 *$ \\
IL-13 & $0+/-0$ & $0+/-0$ & $0+/-0$ & $0+/-0$ & $0+/-0$ \\
IL-17 & $5+/-1$ & $4+/-1$ & $0+/-0$ & $22+/-4 *$ & $18+/-2$ \\
TNF- $\alpha$ & $45.7+/-3.5$ & $47.72+/-1.5$ & $129.94+/-0 *$ & $152.1+/-5.4 *$ & $112.44+/-2.74 *$ \\
KC & $0+/-0$ & $0+/-0$ & $0+/-0$ & $0+/-0$ & $0+/-0$ \\
MCP-1 & $604+/-64$ & $1133+/-303 *$ & $715+/-159$ & $830+/-105 *$ & $941+/-143 *$ \\
M-CSF & $0+/-0$ & $0+/-0$ & $0+/-0$ & $0+/-0$ & $0+/-0$ \\
RANTES & $191+/-14$ & $194+/-22$ & $181+/-8$ & $234+/-17 *$ & $261+/-10 *$ \\
VEGF & $2+/-1$ & $0+/-0$ & $0+/-0$ & $2+/-0$ & $3+/-0$ \\
\hline
\end{tabular}




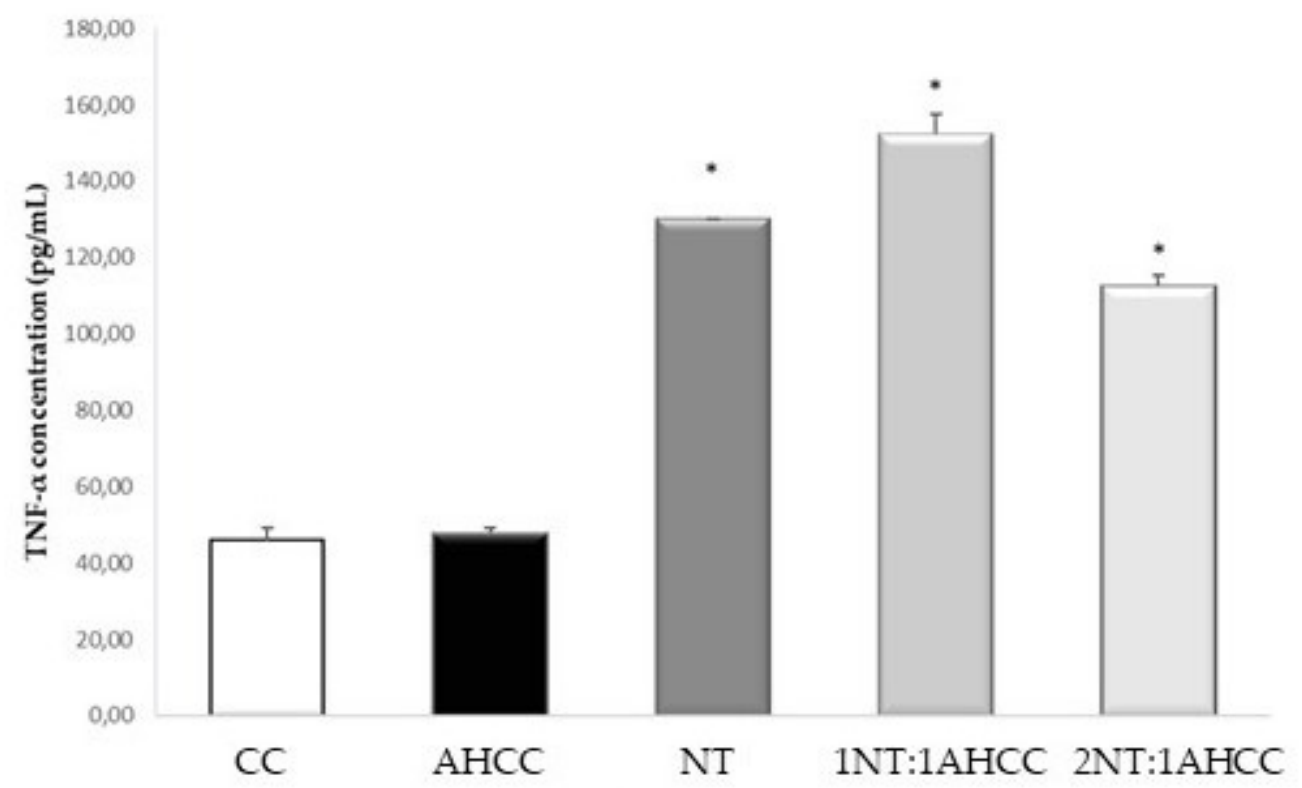

(a)

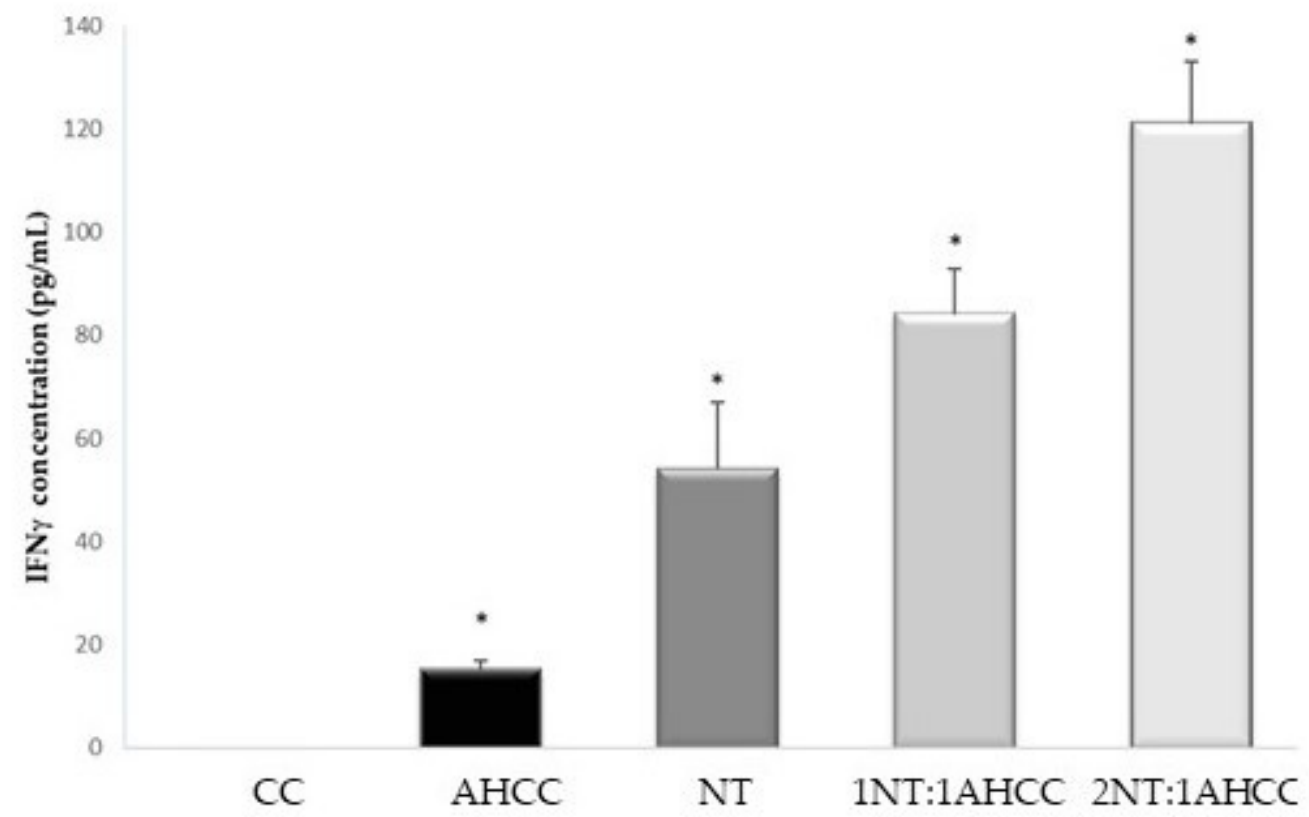

(b)

Figure 3. TNF- $\alpha$ (a) and IFN- $\gamma(\mathbf{b})$ quantification in coculture of lymphocytes and naïve macrophages exposed to nucleotides (NTs) and AHCC, alone or in combination. ${ }^{*} p<0.05$ versus the control.

2.5.2. Coculture of Lymphocytes and Leishmania-Infected Macrophages

A different cytokine stimulation profile was observed in the infected cocultures compared to the noninfected ones (Table 3$)$. TNF- $\alpha$ production was significantly $(p<0.05)$ enhanced by nucleotides, AHCC, and their combinations (Figure 4). IFN- $\gamma$ was increased in the presence of nucleotides, AHCC, and their 2:1 combination (Figure 5). The levels of IL-1 $\alpha$ were also increased by the presence of nucleotides and AHCC, alone and in combination. By contrast, the production of IL- $1 \beta$ was not significantly stimulated in the infected coculture. The levels of IL-6 were enhanced significantly only in the presence of AHCC. 
Table 3. Cytokine quantification after exposure of lymphocytes and L. infantum-infected macrophages to nucleotides (NTs), AHCC, and their combinations. Each value represents the mean $+/-$ standard deviation for three replicates. ${ }^{*} p<0.05$ versus the control.

\begin{tabular}{|c|c|c|c|c|c|c|}
\hline Concentration $(\mathrm{pg} / \mathrm{mL})$ & Noninfected Coculture & Coculture & AHCC & NT & 1NT:1AHCC & 2NT:1AHCC \\
\hline GM-CSF & $0+/-0$ & $0+/-0$ & $0+/-0$ & $0+1-0$ & $0+/-0$ & $0+/-0$ \\
\hline IFN- $\gamma$ & $0+/-0$ & $1+/-0$ & $12+/-2 *$ & $33+/-4 *$ & $1+/-0$ & $5+/-1 *$ \\
\hline IL- $1 \alpha$ & $0+/-0$ & $0+/-0$ & $85+/-83$ * & $97+/-80 *$ & $29+/-12 *$ & $122+/-51 *$ \\
\hline IL- $1 \beta$ & $0+/-0$ & $0+/-0$ & $0+/-0$ & $0+/-0$ & $0+/-0$ & $0+/-0$ \\
\hline IL-2 & $0+/-0$ & $12+/-1 *$ & $0+/-0$ & $0+/-0$ & $0+/-0$ & $0+/-0$ \\
\hline IL-3 & $0+/-0$ & $0+/-0$ & $0+/-0$ & $0+/-0$ & $0+/-0$ & $0+/-0$ \\
\hline $\mathrm{IL}-4$ & $0+/-0$ & $0+/-0$ & $0+/-0$ & $0+/-0$ & $0+/-0$ & $0+/-0$ \\
\hline IL-5 & $0+/-0$ & $0+/-0$ & $0+/-0$ & $0+/-0$ & $3+/-1$ & $0+/-0$ \\
\hline IL-6 & $50+/-6$ & $34+/-4$ & $91+/-19$ * & $43+/-2$ & $57+/-3$ & $44+/-7$ \\
\hline IL-9 & $188+/-29$ & $223+/-37$ & $0+/-0$ & $33+1-3^{*}$ & $161+/-20$ & $53+/-13$ * \\
\hline IL-10 & $0+/-0$ & $2+/-0$ & $0+/-0$ & $10+/-0$ * & $26+/-1 *$ & $0+/-0$ \\
\hline IL-12 & $4+/-1$ & $0+/-0$ & $1+/-0$ & $8+/-1$ & $13+/-1 *$ & $3+/-1$ \\
\hline IL-13 & $0+/-0$ & $0+/-0$ & $0+/-0$ & $0+/-0$ & $0+/-0$ & $0+/-0$ \\
\hline IL-17 & $5+/-1$ & $0+/-0$ & $0+/-0$ & $0+/-0$ & $1+/-0$ & $0+/-0$ \\
\hline TNF- $\alpha$ & $45.7+/-3.5$ & $14.11+/-1.18$ & $117.72+/-10.21$ * & $155.50+/-26.71 *$ & $177.44+/-9.82 *$ & $153.28+/-6.28$ * \\
\hline $\mathrm{KC}$ & $0+/-0$ & $0+/-0$ & $0+/-0$ & $0+/-0$ & $0+/-0$ & $0+/-0$ \\
\hline MCP-1 & $604+/-64$ & $764+/-100$ & $2410+/-327 *$ & $2144+/-269 *$ & $2096+/-540 *$ & $1318+/-546^{*}$ \\
\hline M-CSF & $0+/-0$ & $0+/-0$ & $0+/-0$ & $12+/-2$ & $0+/-0$ & $0+/-0$ \\
\hline RANTES & $191+/-14$ & $149+/-22$ & $347+/-45^{*}$ & $304+/-19 *$ & $308+/-14 *$ & $319+/-22 *$ \\
\hline VEGF & $2+/-1$ & $0+/-0$ & $2+/-0$ & $6+/-1$ & $5+/-1$ & $2+/-0$ \\
\hline
\end{tabular}




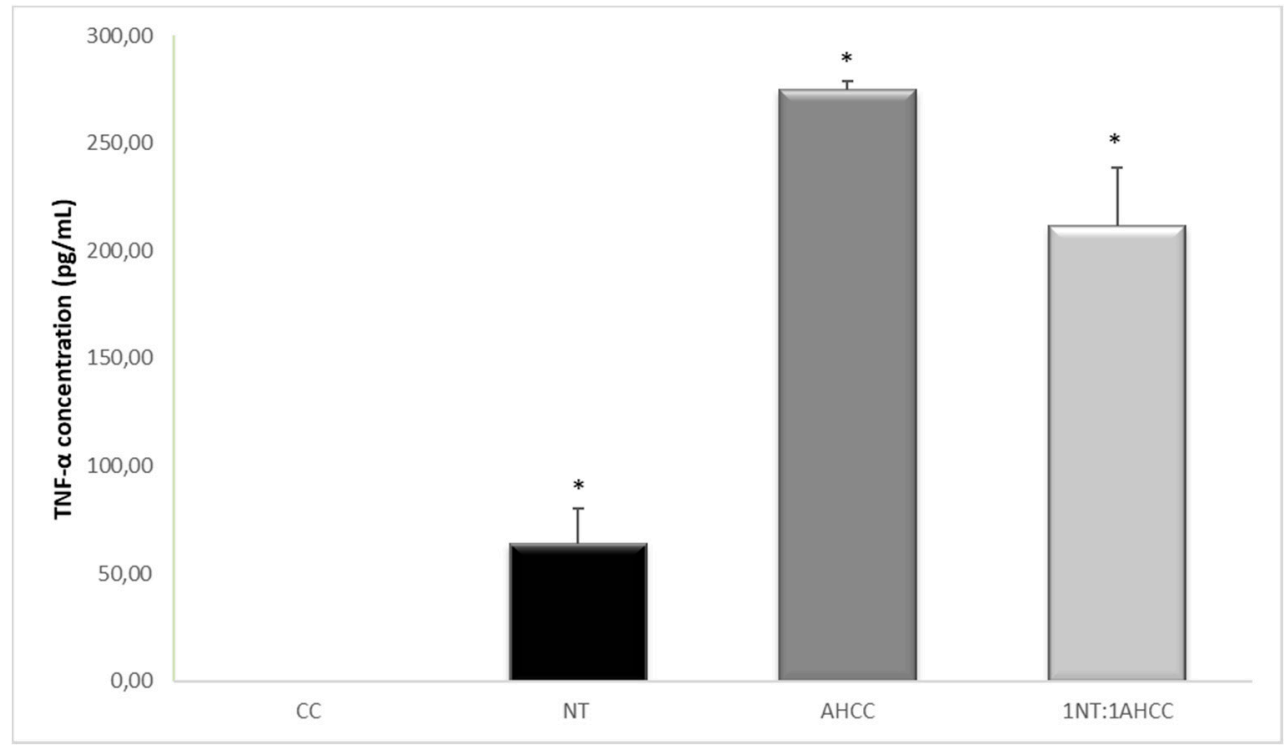

(a)

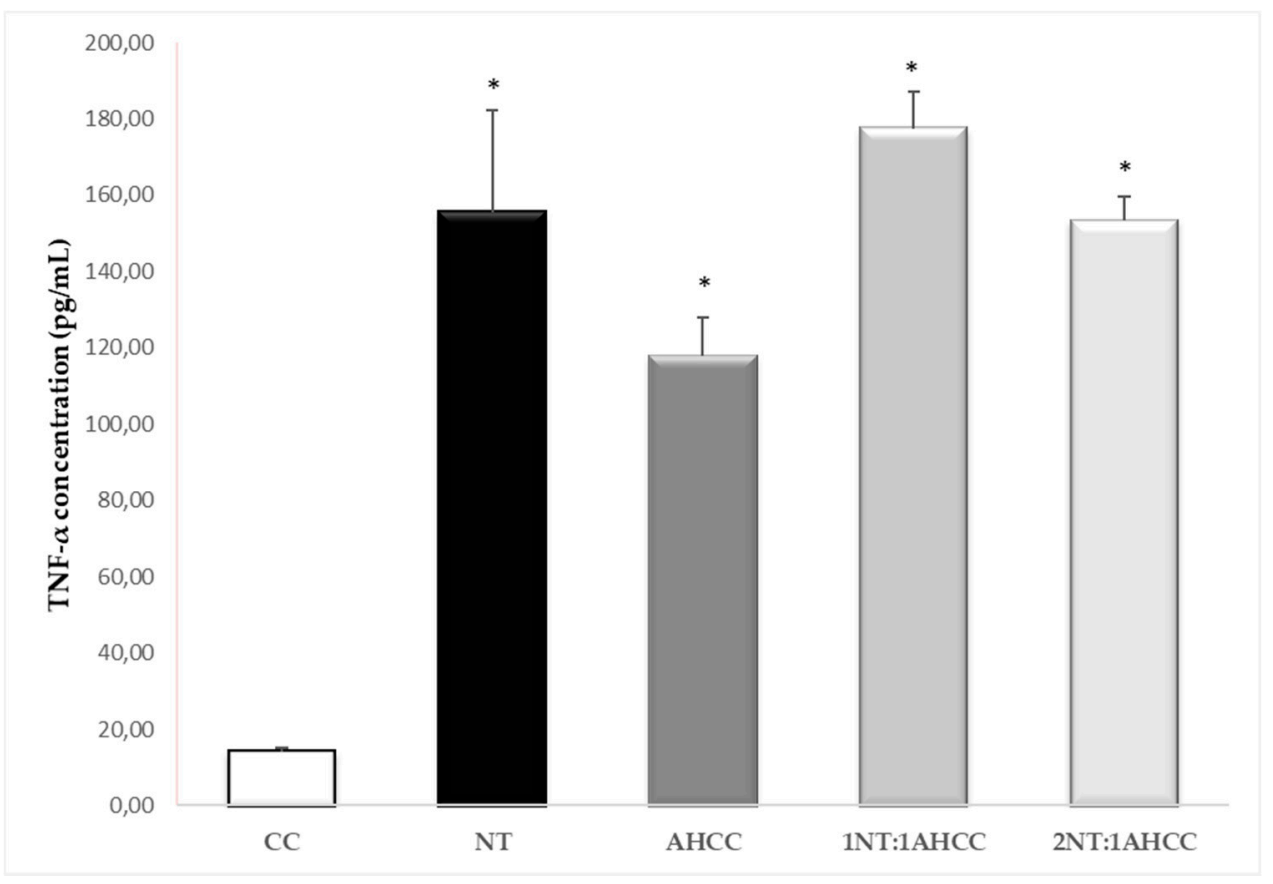

(b)

Figure 4. TNF- $\alpha$ determination after exposure to nucleotides (NTs) and AHCC, alone or in combination in L. infantum-infected macrophages (a) and L. infantum-infected macrophage/lymphocyte cocultures (b). ${ }^{*} p<0.05$ versus the control. 


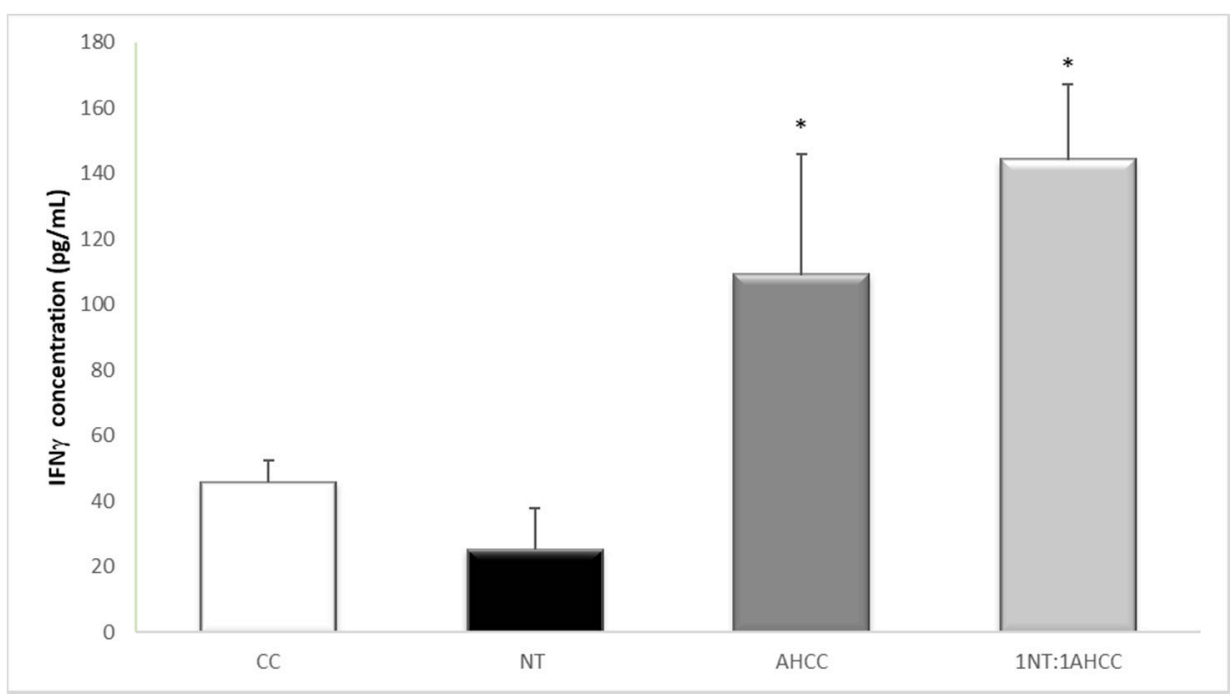

(a)

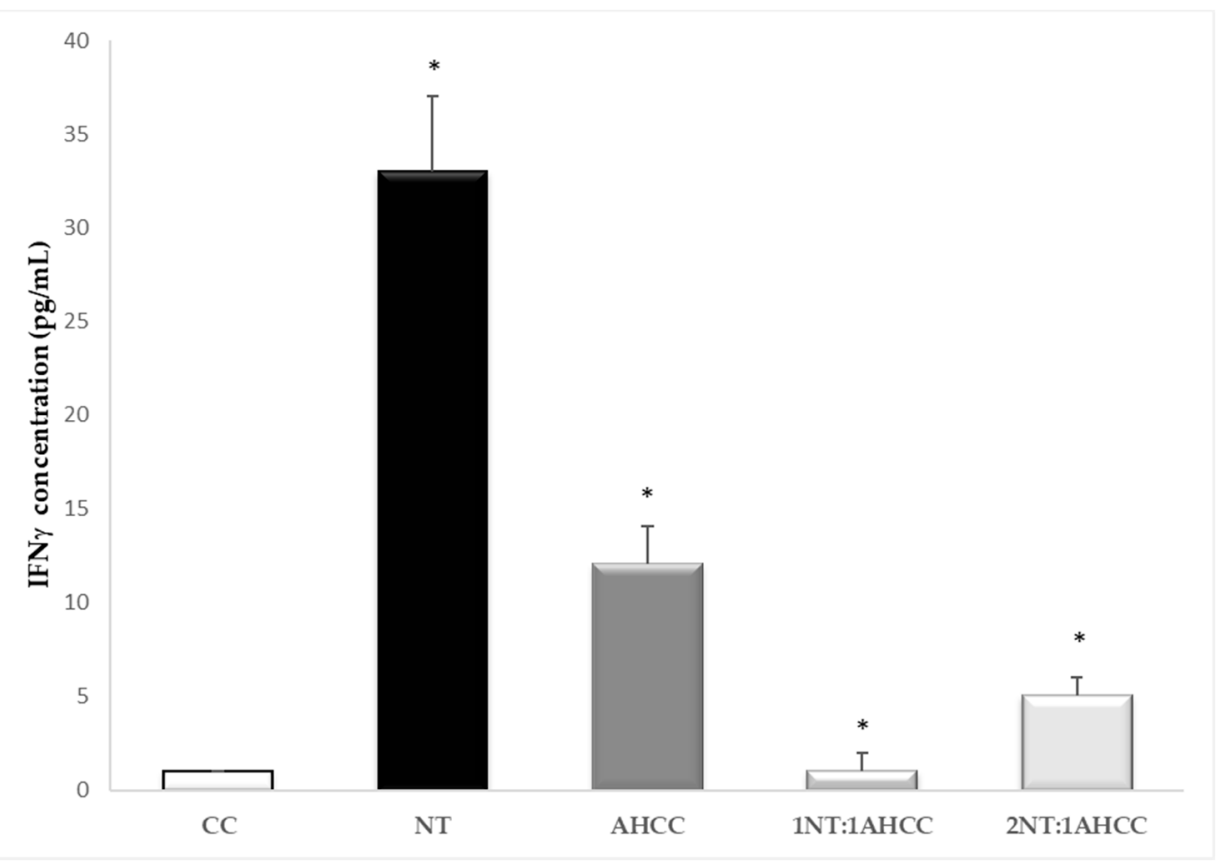

(b)

Figure 5. IFN- $\gamma$ determination after exposure to nucleotides (NTs) and AHCC, alone or in combination, in L. infantum-infected macrophages (a) and L. infantum-infected macrophage/lymphocyte cocultures (b). ${ }^{*} p<0.05$ versus the control.

MCP-1 and RANTES levels were significantly increased with both compounds, alone or in combination. MVA analysis of all cytokine levels showed that most of the variability of the cytokine profile among the different groups was due to the levels of IL-1 $\alpha$, MCP-1, and RANTES (Figure 6). 


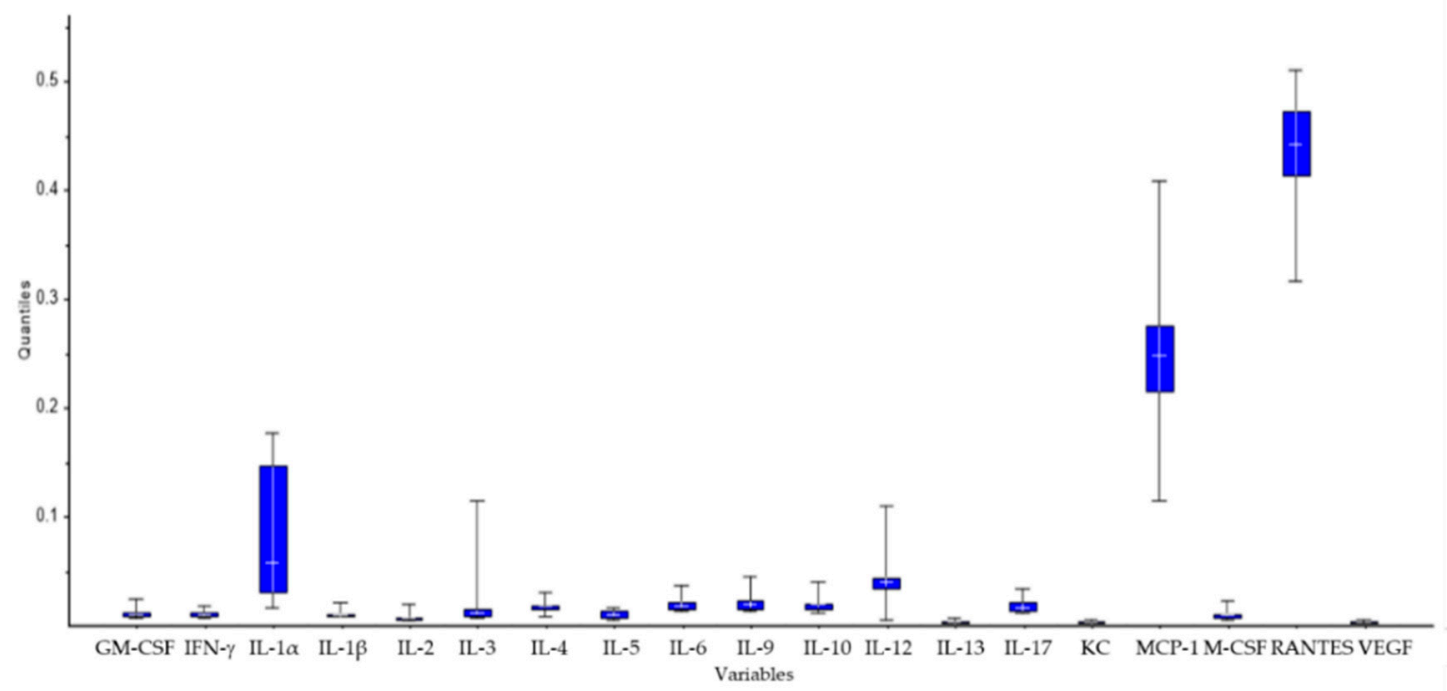

Figure 6. Multivariate analysis on the cytokine profile obtained in Leishmania-infected cocultures of lymphocytes and macrophages in the presence of nucleotides and AHCC.

\section{Discussion}

Leishmania infantum is often considered an opportunistic parasite which benefits from an inadequate immune response, especially in children or immunosuppressed human patients. It is well known that the type of immune response is crucial for the progression and control of the disease. The activation of infected macrophages is required to kill the intracellular Leishmania parasites responsible for the disease [26]. An effective cellular immune response (Th1) is characterized by the release of pro-inflammatory cytokines such as IL-2, IFN- $\gamma$, and TNF- $\alpha$, while the predominance of a Th2 profile is marked by the overexpression of TGF- $\beta$ and IL-10, and is associated with a poorer prognosis [11].

Thereby, immunocompromised patients might benefit from natural compounds that could modulate the immune response towards a Th1 profile. In the in vitro studies reported herein, we have shown that both nucleotides and AHCC are not cytotoxic even at high concentrations, that they enhance lymphocyte proliferation after SLA stimulation, and that they possess the ability of modulating the immune response both in healthy macrophage/lymphocyte cocultures as well as in Leishmania-infected macrophage/lymphocyte cocultures. Our data reveal that there is a synergistic effect between both compounds, and that their 1:1 weight ratio combination leads to the best results. This positive impact on the immune system and enhancement of the Th1 response could explain the beneficial effects previously reported in vivo after the oral administration of nucleotides and AHCC in CanL patients using a similar ratio [24,25]. However, further studies evaluating the specific effects of such compounds on Th1 cells would be warranted.

It is worthy to mention that, according to the results reported herein, none of the tested compounds possess a direct anti-Leishmania activity per se and that they do not promote the NO production by macrophages. The enhanced immune response elicited by nucleotides and AHCC may be related to the IFN- $\gamma$ activation of macrophages leading to TNF- $\alpha$ production, which, in turn, might increase the levels of reactive oxygen species (ROS) in PBMC and, subsequently, result in Leishmania destruction [27].

Prior in vivo benefits observed in dogs could be explained by a combination of factors, such as: stimulation of TNF- $\alpha$, IFN- $\gamma$, MCP-1, RANTES, and IL- $1 \alpha$; decreased IL- 6 and IL-9 levels. Previously, it has been reported that nucleotides play a key role as regulators of immune functions able to increase the Th1/Th2 ratio $[17,28]$. AHCC has also been shown to exert a protective effect against pathogens by enhancing CD4 and CD8 T cell immune responses via increasing the production of TNF- $\alpha$ and IFN- $\gamma$. This protective effect was maintained even 30 days after discontinuing AHCC oral administration [20]. Moreover, it has been shown that AHCC also promotes Thelper (Th17) and Th1 cell responses via 
inducing IL-1 $\beta$ production from monocytes in humans [18]. Surprisingly, this effect was observed in our studies in the naïve cocultures but not in the infected cocultures.

Furthermore, the modulation of the immune system by nucleotides and AHCC appears to be more complex and possibly not only related to the stimulation of IFN- $\gamma$ and TNF- $\alpha$. This is the first report that shows that nucleotides and AHCC elicit a positive effect on MCP-1 and RANTES. The presence of MCP-1 is crucial in regulating Th1/Th2 balance in experimental leishmaniasis and it has been identified as a marker of cure of leishmaniasis in humans [29]. Moreover, in lesions of cutaneous leishmaniasis, a synergistic action has been described between MCP-1 and IFN- $\gamma$ stimulating the killing of parasites by activating monocytes to clear intracellular parasites and promote healing [30]. On the other hand, RANTES also acts as a chemokine able to recruit monocytes/macrophages and eosinophils to the infection site hence being beneficial for the eradication of the parasites [31]. In our studies, nucleotides and AHCC showed the ability to decrease the levels of both IL-6 and IL-9 in infected macrophage/lymphocyte cocultures, which would benefit leishmaniasis patients. IL-9 is a susceptibility factor in Leishmania infection by promoting detrimental Th2 responses [32], and elevated levels of IL-6 have been correlated with a high severity of visceral leishmaniasis [33].

The data reported herein, together with previously published clinical data on the use of nucleotides plus AHCC [24,25], further support the interest of these products for their potential use in the management of canine and human leishmaniasis. The control of such disease is complex due to the heterogeneity of the different species and genotypes and the reported resistance to the most commonly used drugs [34]. Furthermore, this intervention could serve as complementary tool as part of a One Health multimodal approach together with other immunotherapy options [35]. In fact, recent publications include nucleotides and AHCC within the choices of effective immunotherapies for the management and control of CanL [36,37].

\section{Materials and Methods}

\subsection{Compounds}

The compounds used in the study were nucleotides (Nucleoforce ${ }^{\circledR}$ Dogs, Bioiberica S.A.U., Esplugues de Llobregat, Spain) and AHCC ${ }^{\circledR}$ (ECLM, Amino Up Chemical Co. Ltd., Sapporo, Japan).

\subsection{Mice}

BALB/c mice of 6-8 weeks of age were purchased from Harlan Ibérica S.A. (Barcelona, Spain) and allocated in the Animal House Unit of the Complutense University under controlled feeding, light/darkness cycles, and temperature conditions. Animal handling was carried out according to the Principles and Guidelines for the Use of Animals in Research.

\subsection{Cytotoxicity Studies on Murine Macrophages}

The cytotoxicity assay was carried out as previously described [38]. J774 murine macrophages were grown in RPMI 1640 medium supplemented with $10 \%$ heat-inactivated FBS ( $30 \mathrm{~min}$ at $56^{\circ} \mathrm{C}$ ), penicillin $\mathrm{G}(100 \mathrm{U} / \mathrm{mL})$ and streptomycin $(100 \mu \mathrm{g} / \mathrm{mL})$ [25]. For the experiments, cells in the preconfluence phase were harvested with $0.03 \%$ EDTA-0.05\% trypsin in PBS for $20 \mathrm{~min}$. Cell cultures were maintained at $37^{\circ} \mathrm{C}$ in a humidified environment with $5 \% \mathrm{CO}_{2}$ (Hucoa Erlöss, SA/Thermo Fisher Scientific, Madrid, Spain). For evaluation assays, J774 macrophages cell lines were seeded ( $5 \times 104$ cells/well) in 96-well flat-bottom microplates with $100 \mu \mathrm{L}$ RPMI 1640 medium. The cells were allowed to attach for $24 \mathrm{~h}$ at $37^{\circ} \mathrm{C}, 5 \% \mathrm{CO}_{2}$, and the medium was replaced by different concentrations of the compounds resulting in a $200 \mu \mathrm{L}$ total volume with a final concentration identical to the one described above. Macrophages were exposed to the compounds for $24 \mathrm{~h}$. Growth controls were also included. Afterwards, a volume of $20 \mu \mathrm{L}$ of the $2.5 \mathrm{mM}$ resazurin solution was added, and plates were incubated for another $3 \mathrm{~h}$ to evaluate cell viability. The reduction in resazurin was determined by the fluorescence intensity (535 $\mathrm{nm}$ excitation wavelength and $590 \mathrm{~nm}$ emission wavelength). Relative Fluorescence Units 
(RFU) (535-590 nm excitation-emission wavelength) were determined with a fluorimeter (Infinite 200, Tecani-Control, Männedorf, Switzerland). Growth inhibition (\%) was calculated using Equation (1):

$$
\text { Growth inhibition }(\%)=100-\frac{\text { RFU treated wells }- \text { RFU signal to noise }}{\text { RFU untreated }- \text { RFU signal to noise }} \times 100
$$

Each concentration was assayed in triplicate- $400 \mu \mathrm{g} / \mathrm{mL}$ being the highest concentration tested. The medium and drug controls were used in each test as blanks, and the background was subtracted. The $\mathrm{CC}_{50}$ was calculated by probit analysis using SPSS 17.0 Statistics Software.

\subsection{Quantification of NO Production by Macrophages}

Quantification of NO production by macrophages was determined in the supernatants of spleen lymphocytes cultured together with lipopolysaccharide (LPS) or the test compounds (nucleotides, AHCC and their combination) for $24 \mathrm{~h}$ by using a Griess test [39]. An aliquot of $100 \mu \mathrm{L}$ was incubated with $100 \mu \mathrm{L}$ Griess reagent (1\% sulfanilamide, 0.1\% N-(1-naphthyl)ethylenediamine dihydrochloride in $2.5 \%$ ortho-phosphoric acid) for $5 \mathrm{~min}$ in darkness. Absorbance was measured at $570 \mathrm{~nm}$.

\subsection{In Vitro Promastigote and Amastigote Susceptibility Assays}

In vitro activity studies were performed using L. braziliensis, L. amazonensis, L. infantum, and L. donovani as previously described $[40,41]$. Nucleotides and AHCC, alone or in combination (1:1, 2:1, 3:1, 1:3, and 1:2 w:w ratio), were diluted in culture media and tested at different concentrations starting at $200 \mu \mathrm{g} / \mathrm{mL}$. Briefly, against extracellular promastigotes, $2.5 \times 10^{6}$ parasites/well were seeded in 96-well microliter plates. The compounds were dissolved in DMSO and diluted in the culture medium at concentrations ranging from 100 to $0.8 \mu \mathrm{g} / \mathrm{mL}$ in a final volume of $200 \mu \mathrm{L}$. After incubation for $48 \mathrm{~h}$ at $26^{\circ} \mathrm{C}, 20 \mu \mathrm{L}$ of the $2.5 \mathrm{mM}$ resazurin solution was added to each well and incubated for $3 \mathrm{~h}$. The fluorescence intensity (535 nm excitation wavelength and $590 \mathrm{~nm}$ emission wavelength) was measured in a fluorometer (Infinite 200, Tecan Group Ltd., Männedorf, Switzerland). All assays were carried out in triplicate. Against intracellular amastigotes, $5 \times 10^{4}$ macrophages and stationary promastigotes were seeded in a 1:10 ratio in each well of a microtiter plate, suspended in $200 \mu \mathrm{L}$ culture medium and incubated for $24 \mathrm{~h}$ at $33{ }^{\circ} \mathrm{C}, 5 \% \mathrm{CO}_{2}$ in a humidity chamber. After this first incubation, temperature was increased up to $37^{\circ} \mathrm{C}$ for another $24 \mathrm{~h}$. Thereafter, cells were washed several times in culture medium by centrifugation at $125 \times g$ for $5 \mathrm{~min}$ in order to remove free noninfective promastigotes. Finally, the supernatant was replaced by $200 \mu \mathrm{L} /$ well culture medium containing compounds to be tested followed by incubation for $48 \mathrm{~h}$. Then, the supernatants were collected and stored at $-80^{\circ} \mathrm{C}$ for cytokine quantification. After incubation of the plates for $48 \mathrm{~h}$ at $37^{\circ} \mathrm{C}$ in $5 \% \mathrm{CO}_{2}$, the culture medium was replaced with an equal volume of lysis solution (Schneider's with $0.048 \%$ HEPES and $0.01 \% \mathrm{SDS}$ ) and maintained at room temperature for $20 \mathrm{~min}$. The lysis solution was then replaced with Schneider's medium followed by incubation at $26^{\circ} \mathrm{C}$ for another 3 days to allow the transformation of viable amastigotes into promastigotes and their subsequent proliferation. Aliquots of $20 \mu \mathrm{L}$ of $2.5 \mathrm{mM}$ resazurin were added to each well, and the plates were incubated for $3 \mathrm{~h}$. Finally, fluorescence emission was measured as described above. All assays were carried out in triplicate. The half maximal inhibitory concentration $\left(\mathrm{IC}_{50}\right)$ was determined by a probit analysis.

\subsection{Preparation of Leishmania Infantum Antigen}

Soluble Leishmania infantum antigens (SLAs) were prepared from stationary promastigotes of $\mathrm{M} / \mathrm{CAN} / \mathrm{ES} / 96 / \mathrm{BCN} 150$ isolate of $L$. infantum cultured in Schneider medium to which HEPES (4 g/L), sodium bicarbonate $(0.4 \mathrm{~g} / \mathrm{L}), 10 \% \mathrm{SBF}$, and antibiotics were added. After washing several times in PBS pH 7.2-7.4, the parasite suspension, kept on ice, was sonicated until a visible decrease in viscosity was achieved. Subsequently, overnight extraction was performed at $4{ }^{\circ} \mathrm{C}$ in $0.5 \mathrm{M}$ Tris- $\mathrm{HCl}$ buffer $\mathrm{pH}$ 
7.5 followed by centrifugation at $13,200 \times g$ for $1 \mathrm{~h}$, and then, the supernatant was collected. Protein content was estimated by the Bradford assay.

\subsection{In Vitro Lymphoproliferation Assay}

One BALB/c mouse spleen was homogenized through a stainless-steel tissue grinder in RPMI medium supplemented with $2 \mathrm{mmol} / \mathrm{L}$ L-glutamine, $10 \mathrm{mmol} / \mathrm{L}$ Hepes, sodium bicarbonate $(2.2 \mathrm{~g} / \mathrm{L})$, and gentamicin $(50 \mu \mathrm{g} / \mathrm{mL})$. The cell suspension was treated with $\mathrm{NH} 4 \mathrm{Cl}$ at $0.8 \%$ to remove red cells, and thereafter, cells were washed three times in RPMI by centrifugation at $125 \times g$ for 5 min. After washing, cells were counted using the Newbauer hemocytometer and their viability was determined by Trypan blue staining exclusion. Cell suspensions were adjusted to a concentration of $5 \times 10^{5} \mathrm{cell} / \mathrm{mL}$ and then dispensed to $96-$ well microtiter plates (Sarstedt, Barcelona, Spain). LPS (Sigma, Madrid, Spain) and SLAs were used at concentrations of 2.5 and $20 \mu \mathrm{g} / \mathrm{mL}$, respectively. Plates were incubated a $37^{\circ} \mathrm{C}, 5 \% \mathrm{CO}_{2}$ for 3 days. Following incubation, a volume of $20 \mu \mathrm{L}$ of the $2.5 \mathrm{mM}$ resazurin solution in PBS was added, and the plates were incubated for $3 \mathrm{~h}$ under the same conditions. The reduction in resazurin was determined as described above.

\subsection{Coculture of Macrophages and Lymphocytes}

In this study, we adapted a method from Viana et al., 2013 [42]. Briefly, lymphocytes from $\mathrm{BALB} / \mathrm{c}$ spleen and J774 macrophages were used. Two different coculture systems were tested: lymphocyte/naïve macrophages and lymphocyte/L. infantum-infected macrophages. A 1:1 ratio was used in both systems. Both culture systems were incubated for $48 \mathrm{~h}$ with nucleotides and AHCC, and after this period, the supernatants were collected and stored at $-80^{\circ} \mathrm{C}$ for cytokines quantification.

\subsection{Analysis of Cytokines}

The level of cytokines was determined in the supernatants of spleen lymphocytes cultured with LPS or compounds (nucleotides, AHCC or both). After incubation for $24 \mathrm{~h}$, the supernatants were collected and stored at $-80{ }^{\circ} \mathrm{C}$ for cytokine quantification. The analyses were carried out by using the Quantibody ${ }^{\circledR}$ array (RayBiotech, Madrid, Spain), a multiplexed sandwich ELISA-based quantitative array platform. Nineteen different markers were analyzed: granulocyte-macrophage colony-stimulating factor (GM-CSF); IFN- $\gamma$; interleukins (IL) IL-1 $\alpha$, IL-1 $\beta$, IL-2, IL-3, IL-4, IL-5, IL-6, IL-9, IL-10, IL-12, IL-13, and IL-17; growth-regulated alpha protein (KC); monocyte chemoattractant protein-1 (MCP-1); macrophage colony-stimulating factor (M-CSF), regulated on activation; normal $\mathrm{T}$ cell expressed and secreted (RANTES); and vascular endothelial growth factor (VEGF). A pair of cytokine specific antibodies was used for detection. A capture antibody was first bound to the glass surface. After incubation with the sample, the target cytokine was trapped on the solid surface. A second biotin-labeled detection antibody was added, which recognized a different epitope of the target cytokine. The cytokine-antibody-biotin complex was visualized through the addition of the streptavidin-conjugated Cy3 equivalent dye, using a laser scanner (GenePix ${ }^{\circledR} 4000 \mathrm{~B}$ Scanner, UCM facilities).

A sandwich ELISA kit was used to determine the concentrations of TNF- $\alpha$. The procedure was carried out according the manufacturer's instructions. Briefly, standards and samples $(50 \mu \mathrm{L})$ were diluted with $50 \mu \mathrm{L}$ commercial diluting solution in triplicate and incubated for $2 \mathrm{~h}$ at $37^{\circ} \mathrm{C}$. Plates were washed five times and $100 \mu \mathrm{L}$ conjugated anti-TNF- $\alpha$ was added and incubated for $1 \mathrm{~h}$ at $37^{\circ} \mathrm{C}$. Finally, $100 \mu \mathrm{L}$ TMB was added as substrate and incubated for $30 \mathrm{~min}$ in the dark at room temperature. The reaction was stopped with $3 \mathrm{~N} \mathrm{H}_{2} \mathrm{SO}_{4}$, and the optical densities (OD) were read at $450 \mathrm{~nm}$.

\subsection{Statistical Data Analysis}

Lymphoproliferation results were analyzed by a Mann-Whitney U test. A multivariate data analysis was performed using The Unscrambler ${ }^{\circledR} \mathrm{X}$ software (CAMO Software, Oslo, Norway). The cytokine profile of infected macrophage/lymphocyte cocultures was analyzed by Principal 
Component Analysis (PCA) in order to the study systematic variability and the relationships between variables and scores (presence of nucleotides and AHCC and their combinations). A Singular Value Decomposition algorithm was employed. The correlation loadings of the PCAs were represented to understand the variance for each variable for a given PCA, giving information about the source of the variability inside the dataset.

\section{Conclusions}

Nucleotides and AHCC showed the ability to enhance an effective Th1 immune response in vitro by increasing TNF- $\alpha$, IFN- $\gamma$, MCP-1, RANTES, and IL- $1 \alpha$ levels while reducing IL- 6 and IL- 9 cytokine levels in Leishmania-stimulated/infected murine immune cells. Since a stronger cellular immune response in leishmaniasis is associated with a better prognosis, the combination of nucleotides plus AHCC could be beneficial for the prevention and management of CanL, and it might also be helpful in human visceral leishmaniasis.

Supplementary Materials: The following are available online, S1: Cytotoxicity studies on murine macrophages. S2: Production of NO by macrophages. S3: In vitro promastigote and amastigote susceptibility assays.

Author Contributions: Conceptualization: S.S., M.A.D.-A., and F.B.-F.; investigation and resources: M.A.D.-A., S.S., and F.B.-F; data evaluation: M.A.D.-A., S.S.; D.R.S., and F.B.-F.; writing-original draft preparation: D.R.S. and M.A.D.-A.; writing — review and editing: S.S., F.B.-F., and D.R.S.; supervision: S.S. and F.B.-F. All authors have read and agreed to the published version of the manuscript.

Funding: This research was funded by Bioiberica S.A.U., Esplugues de Llobregat (Spain).

Conflicts of Interest: S.S. is employed by Bioiberica S.A.U. The rest of the authors state no conflict of interest.

\section{References}

1. Maslov, D.A.; Opperdoes, F.R.; Kostygov, A.Y.; Hashimi, H.; Lukeš, J.; Yurchenko, V. Recent advances in trypanosomatid research: Genome organization, expression, metabolism, taxonomy and evolution. Parasitology 2019, 146, 1-27. [CrossRef] [PubMed]

2. Lukeš, J.; Butenko, A.; Hashimi, H.; Maslov, D.A.; Votýpka, J.; Yurchenko, V. Trypanosomatids are much more than just trypanosomes: Clues from the expanded family tree. Trends Parasitol. 2018, 34, 466-480. [CrossRef] [PubMed]

3. Young, D.G.; Lawyer, P.G. New world vectors of the Leishmaniases. In Current Topics in Vector Research, 1st ed.; Harris, K.F., Ed.; Springer: New York, NY, USA, 1987; Volume 4, pp. $29-71$.

4. Bañuls, A.L.; Bastien, P.; Pomares, C.; Arevalo, J.; Fisa, R.; Hide, M. Clinical pleiomorphism in human leishmaniases, with special mention of asymptomatic infection. Clin. Microbiol. Infect. 2011, 17, 1451-1461. [CrossRef]

5. Barbosa, J.F.; de Figueiredo, S.M.; Monteiro, F.M.; Rocha-Silva, F.; Gaciele-Melo, C.; Coelho, S.S.; Lyon, S.; Caligiorne, R.B. New approaches on leishmaniasis treatment and prevention: A review of recent patents. Recent Pat. Endocr. Metab. Immune Drug Discov. 2015, 9, 90-102. [CrossRef]

6. Manna, L.; Corso, R.; Galiero, G.; Cerrone, A.; Muzj, P.; Gravino, A.E. Long-term follow-up of dogs with leishmaniosis treated with meglumine antimoniate plus allopurinol versus miltefosine plus allopurinol. Parasites Vectors 2015, 8, 289-298. [CrossRef]

7. Reguera, R.M.; Morán, M.; Pérez-Pertejo, Y.; García-Estrada, C.; Balaña-Fouce, R. Current status on prevention and treatment of canine leishmaniasis. Vet. Parasitol. 2016, 227, 98-114. [CrossRef]

8. Baneth, G.; Aroch, I. Canine leishmaniasis: A diagnostic and clinical challenge. Vet. J. 2008, 175, 14-15. [CrossRef]

9. Yasur-Landau, D.; Jaffe, C.L.; David, L.; Baneth, G. Allopurinol resistance in Leishmania infantum from dogs with disease relapse. PLoS Negl. Trop. Dis. 2016, 10, e0004341. [CrossRef]

10. Sindermann, H.; Engel, J. Development of miltefosine as an oral treatment for leishmaniasis. Trans. R. Soc. Trop. Med. Hyg. 2006, 100, S17-S20. [CrossRef]

11. Reis, A.B.; Giunchetti, R.C.; Carrillo, E.; Martins-Filho, O.A.; Moreno, J. Immunity to Leishmania and the rational search for vaccines against canine leishmaniasis. Trends Parasitol. 2010, 26, 341-349. [CrossRef] 
12. Reis, M.L.; Ferreira, V.M.; Zhang, X.; Gonçalves, R.; Vieira, L.Q.; Tafuri, W.L.; Mosser, D.M.; Tafuri, W.L. Murine immune response induced by Leishmania major during the implantation of paraffin tablets. Virchows Arch. 2010, 457, 609-618. [CrossRef]

13. Manna, L.; Reale, S.; Picillo, E.; Vitale, F.; Gravino, A.E. Interferon-gamma (INF-gamma), IL4 expression levels and Leishmania DNA load as prognostic markers for monitoring response to treatment of leishmaniotic dogs with miltefosine and allopurinol. Cytokine 2008, 44, 288-292. [CrossRef]

14. Esch, K.J.; Juelsgaard, R.; Martinez, P.A.; Jones, D.E.; Petersen, C.A. Programmed death 1-mediated T cell exhaustion during visceral leishmaniasis impairs phagocyte function. J. Immunol. 2013, 191, 5542-5550. [CrossRef]

15. Hess, J.R.; Greenberg, N.A. The role of nucleotides in the immune and gastrointestinal systems potential clinical applications. Nutr. Clin. Pract. 2012, 27, 281-294. [CrossRef]

16. Martínez-Augustín, O.; Gil, A. Role of dietary nucleotides in immunity. Funct. Food Rev. 2010, 2, 91-100.

17. Gil, A. Modulation of the immune response mediated by dietary nucleotides. Eur. J. Clin. Nutr. 2002, 56, S1-S4. [CrossRef]

18. Smith, J.A.; Mathew, L.; Gaikwad, A.; Rech, B.; Burney, M.N.; Faro, J.P.; Lucci, J.A., 3rd; Bai, Y.; Olsen, R.J.; Byrd, T.T. From bench to bedside: Evaluation of AHCC supplementation to modulate the host immunity to clear high-risk human papillomavirus infections. Front. Oncol. 2019, 9, 173. [CrossRef]

19. Lee, W.W.; Lee, N.; Fujii, H.; Kang, I. Active hexose correlated compound promotes T helper (Th) 17 and 1 cell responses via inducing IL-1 $\beta$ production from monocytes in humans. Cell Immunol. 2012, 275, 19-23. [CrossRef]

20. Ulbricht, C.; Brigham, A.; Bryan, J.K.; Catapang, M.; Chowdary, D.; Costa, D.; Culwell, S.; D'Auria, D.; Giese, N.; Iovin, R.; et al. An evidence-based systematic review of active hexose correlated compound (AHCC) by the Natural Standard Research Collaboration. J. Diet. Suppl. 2013, 10, 264-308. [CrossRef]

21. Yin, Z.; Fujii, H.; Walshe, T. Effects of active hexose correlated compound on frequency of CD4+ and CD8+ $\mathrm{T}$ cells producing interferon- $\gamma$ and/or tumor necrosis factor- $\alpha$ in healthy adults. Hum. Immunol. 2010, 71, 1187-1190. [CrossRef]

22. Daddaoua, A.; Martínez-Plata, E.; Ortega-González, M.; Ocón, B.; Aranda, C.J.; Zarzuelo, A.; Suárez, M.D.; de Medina, F.S.; Martínez-Augustin, O. The nutritional supplement active hexose correlated compound (AHCC) has direct immunomodulatory actions on intestinal epithelial cells and macrophages involving TLR/MyD88 and NF-kB/MAPK activation. Food Chem. 2013, 136, 1288-1295. [CrossRef] [PubMed]

23. Mallet, J.F.; Graham, É.; Ritz, B.W.; Homma, K.; Matar, C. Active hexose correlated compound (AHCC) promotes an intestinal immune response in BALB/c mice and in primary intestinal epithelial cell culture involving toll-like receptors TLR-2 and TLR-4. Eur. J. Nutr. 2016, 55, 139-146. [CrossRef] [PubMed]

24. Segarra, S.; Miró, G.; Montoya, A.; Pardo-Marín, L.; Boqué, N.; Ferrer, L.; Cerón, J. Randomized, allopurinolcontrolled trial of the effects of dietary nucleotides and active hexose correlated compound in the treatment of canine leishmaniosis. Vet. Parasitol. 2017, 239, 50-56. [CrossRef] [PubMed]

25. Segarra, S.; Miró, G.; Montoya, A.; Pardo-Marín, L.; Teichenné, J.; Ferrer, L.; Cerón, J.J. Prevention of disease progression in Leishmania infantum-infected dogs with dietary nucleotides and active hexose correlated compound. Parasites Vectors 2018, 11, 103. [CrossRef]

26. Liu, D.; Uzonna, J.E. The early interaction of Leishmania with macrophages and dendritic cells and its influence on the host immune response. Cell. Infect. Microbiol. 2012, 12, 83-90. [CrossRef]

27. Melo, L.M.; Perosso, J.; Almeida, B.F.; Silva, K.L.; Somenzari, M.A.; de Lima, V.M. Effects of P-MAPA immunomodulator on Toll-like receptor 2, ROS, nitric oxide, MAPKp38 and IKK in PBMC and macrophages from dogs with visceral leishmaniasis. Int. Immunopharmacol. 2014, 18, 373-378. [CrossRef]

28. Jyonouchi, H.; Sun, S.; Winship, T.; Kuchan, M.J. Dietary ribonucleotides increase antigen-specific type 1 T-helper cells in the regional draining lymph nodes in young BALB/cJ mice. Nutrition 2003, 19, 41-46. [CrossRef]

29. Ibarra-Meneses, A.V.; Sanchez, C.; Alvar, J.; Moreno, J.; Carrillo, E. Monocyte Chemotactic Protein 1 in plasma from soluble Leishmania antigen-stimulated whole blood as a potential biomarker of the cellular immune response to Leishmania infantum. Front. Immunol. 2017, 8, 1208-1212. [CrossRef]

30. Ritter, U.; Moll, H. Monocyte chemotactic protein-1 stimulates the killing of Leishmania major by human monocytes, acts synergistically with IFN-gamma and is antagonized by IL-4. Eur. J. Immunol. 2000, 30, 3111-3120. [CrossRef] 
31. Matte, C.; Olivier, M. Leishmania-induced cellular recruitment during the early inflammatory response: Modulation of proinflammatory mediators. J. Infect. Dis. 2002, 185, 673-681. [CrossRef]

32. Arendse, B.; Van Snick, J.; Brombacher, F. IL-9 is a susceptibility factor in Leishmania infection by promoting detrimental Th2/type 2 responses. J. Immunol. 2005, 174, 2205-2211. [CrossRef]

33. Dos Santos, P.L.; de Oliveira, F.A.; Santos, M.L.; Cunha, L.C.; Lino, M.T.; De Oliveira, M.F.; Bomfim, M.O.; Silva, A.M.; De Moura, T.R.; De Jesus, A.R.; et al. The severity of visceral leishmaniasis correlates with elevated levels of serum IL-6, IL-27 and sCD14. PLoS Negl. Trop. Dis. 2016, 10, e0004375. [CrossRef]

34. Maia, C.; Nunes, M.; Marques, M.; Henriques, S.; Rolão, N.; Campino, L. In vitro drug susceptibility of Leishmania infantum isolated from humans and dogs. Exp. Parasitol. 2013, 135, 36-41. [CrossRef]

35. Borja-Cabrera, G.P.; Santos, F.N.; Santos, F.B.; Trivellato, F.A.; Kawasaki, J.K.; Costa, A.C.; Castro, T.; Nogueira, F.S.; Moreira, M.A.; Luvizotto, M.C.; et al. Immunotherapy with the saponin enriched-Leishmune vaccine versus immunochemotherapy in dogs with natural canine visceral leishmaniasis. Vaccine 2010, 28, 597-603. [CrossRef]

36. Baxarias, M.; Martínez-Orellana, P.; Baneth, G.; Solano-Gallego, L. Immunotherapy in clinical canine leishmaniosis: A comparative update. Res. Vet. Sci. 2019, 125, 218-226. [CrossRef]

37. Dantas-Torres, F.; Miró, G.; Baneth, G.; Bourdeau, P.; Breitschwerdt, E.; Capelli, G.; Cardoso, L.; Day, M.J.; Dobler, G.; Ferrer, L.; et al. Canine leishmaniasis control in the context of One Health. Emerg. Infect. Dis. 2019, 25, 1-4. [CrossRef]

38. Dea-Ayuela, M.A.; Castillo, E.; Gonzalez-Alvarez, M.; Vega, C.; Rolón, M.; Bolás-Fernández, F.; Borrás, J.; González-Rosende, M.E. In vivo and anti-leishmanial activities of 4-nitro-N-pyrimidin- and N-pyrazin-2-ylbenzenesulfonamides, and N2- 4-nitrophenyl)-N1-propylglycinamide. Bioorg. Med Chem. 2009, 17, 7449-7456. [CrossRef]

39. Galiana-Roselló, C.; Bilbao-Ramos, P.; Dea-Ayuela, M.A.; Rolón, M.; Vega, C.; Bolás-Fernández, F.; García-España, E.; Alfonso, J.; Coronel, C.; González-Rosende, M.E. In vitro and in vivo antileishmanial and trypanocidal studies of new N-benzene- and N-naphthalenesulfonamide derivatives. J. Med. Chem. 2013, 56, 8984-8998. [CrossRef]

40. Serrano, D.R.; Lalatsa, A.; Dea-Ayuela, M.A. Engineering synergistically active and bioavailable cost-effective medicines for neglected tropical diseases: The role of excipients. Curr. Top. Med. Chem. 2017, 17, 2888-2900. [CrossRef]

41. Bilbao-Ramos, P.; Sifontes-Rodríguez, S.; Dea-Ayuela, M.A.; Bolás-Fernández, F. A fluorometric method for evaluation of pharmacological activity against intracellular Leishmania amastigotes. J. Microbiol. Methods 2012, 89, 8-11. [CrossRef]

42. Viana, K.F.; Aguiar-Soares, R.D.; Roatt, B.M.; Resende, L.A.; da Silveira-Lemos, D.; Corrêa-Oliveira, R.; Martins-Filho, O.A.; Moura, S.L.; Zanini, M.S.; Araújo, M.S.; et al. Analysis using canine peripheral blood for establishing in vitro conditions for monocyte differentiation into macrophages for Leishmania chagasi infection and T-cell subset purification. Vet Parasitol. 2013, 98, 62-71. [CrossRef]

Sample Availability: Samples of the compounds in these studies are available from the authors.

(C) 2020 by the authors. Licensee MDPI, Basel, Switzerland. This article is an open access article distributed under the terms and conditions of the Creative Commons Attribution (CC BY) license (http://creativecommons.org/licenses/by/4.0/). 